\section{Attributes of a Relationship Management Model for the Public Sector (CiRS Exec)}

\author{
Júlio Medeiros ${ }^{1}$ \\ julioelpidio@gmail.com| (10000-0002-1208-6740 \\ Gisela Demo ${ }^{1}$ \\ giselademo@unb.br|®0000-0003-1864-0471
}

\begin{abstract}
The New Public Management has encouraged the adoption of managerial tools by the public administration. In this context, the Citizen Relationship Management (CiRM) strategy allows for the improvement of the relationship with citizens and encourages citizenship. Thus, this research aims at identifying evidence for validity and reliability of a citizen relationship scale (CiRS Exec) for the Federal Executive Branch in Brazil, as well as a citizen's satisfaction index. Exploratory and confirmatory factor analyses have been used, through structural equation modeling. The measurement model has presented good adjustment and a unifactorial structure scale named 'Citizen Relationship', comprising 13 items.
\end{abstract}

\section{KEYWORDS}

CiRM, relationship management, relationship scale, citizen, public service
${ }^{1}$ Programa de Pós-Graduação em Administração (PPGA) Universidade de Brasília, Brasília, DF, Brasil

Received: 08/28/2019.

Revised: $11 / 25 / 2019$.

Accepted: 05/13/2020.

Published Online: 11/30/2020.

DOI: http://dx.doi.org/10.15728/bbr.2021.18.1.6 


\section{INTRODUCTION}

The New Public Management (NPM) has emerged as a result of the limitation of the bureaucratic model of public administration for meeting society's demands, as well as being due to the economic crisis faced by multiple countries (Hood, 1991). The NPM appeared in the early 1980s and fostered the implementation of concepts and practices focused on the performance of public administration, through the introduction of private methods of management in the public sector, in order to guarantee the provision of better public services (Pollit, 2013).

Since then, public managers have pursued the improvement of the strategy as to guarantee citizen-centered public services. In this context, the philosophy of the Citizen Relationship Management (CiRM) arises, inspired by the private sector experience of Customer Relationship Management (CRM). CRM is supported by technology information tools and aims at establishing, maintaining, and enhancing relationships, as well as helping to retain customers, pursue their loyalty and increase profits (Mishra \& Mishra, 2009; Schellong, 2005).

Some researchers argue that CiRM strategy appears as a result of the debate brought by the NPM paradigm (Reddick, 2010; Schellong, 2005). Therefore, the CiRM helps improve service levels and relationships with citizens, securing better quality and more efficient public services, as well as promoting citizenship and enhancing image/credibility in public services (Demo \& Pessôa, 2015; Schellong, 2008). By adopting a CiRM strategy, citizen orientation is sought, not only to promote accountability, but also to influence citizen's perceptions about their relationship with the government (Nassif, 2004; Schellong, 2008).

Therefore, this research aims at identifying evidence of validity and reliability in a citizen relationship scale (CiRS Exec) for the Federal Executive Branch in Brazil, once such gap has been appointed by Demo and Pessoa (2015), with regards to diagnostic instruments within public bodies in the Executive Branch. The CiRS Exec development has been performed by using previous models, which have been validated by Demo and Pessoa (2015), for the Federal Judiciary Branch, and by Lara and Gosling (2016), set for the government of Minas Gerais State in Brazil. These are known as the only initiatives found in the literature. Further, the citizens' satisfaction index has been evaluated based on the Net Promoter Score (NPS) index, as proposed by Reichheld (2012).

In practical terms, the scale we present contributes to the ongoing discussion regarding the CiRM strategy within the Brazilian government. This research offers a scientifically validated instrument for promoting a qualified process of research that may help improve the relationship between governments and citizens.

\section{THEORETICAL FRAMEWORK}

\subsection{New Public Management}

The early 1980s set a challenging scenario for governments worldwide. On one hand, countries were facing severe budget constraints as well as a fiscal crisis, and, on the other, citizens were requiring better delivery of public services. This has promoted the debate aimed at reestablishing the foundations and principles within the Public Administration. This new paradigm has been known as the New Public Administration (NPM) and was inspired by technologies drawn from the private sector, fostering the construction of a more agile and entrepreneurial state, one which is able to face citizens' growing demands (Hood, 1995; Pollit \& Dan, 2013). 
Thus, the NPM aimed at defining a new model to help public managers overcome the limitations of the bureaucratic model, allegedly to be hierarchical and process-driven (Hood, 1991; Vigoda, 2002). Hood (1991) and Pollit and Dan (2013) advocate that the emergence of a post-bureaucratic paradigm in countries like the United Kingdom and United States may be seen as the need to resize the state apparatus. Furthermore, partnerships with the private sector in providing public services, as well as the support of information technology, were introduced as alternatives tothe process of delivering public services. Such debate strengthened the need for a new approach in public management, evolving from a process-driven approach to a more results-based strategy (Hood, 1991, 1995).

In Brazil, the New Public Management propositions guided the edition of the Directive Plan for the Reform of the State Apparatus (PDRAE), in 1995, which aimed at reducing the state's activities, from a modern perspective, with a focus on the quality and productivity of the public service. The project's main goal was to introduce values and practices pointed by the Managerial Public Administration, as well as efficiency and result-based accountability, allowing decentralization strategies to government activities, so that citizens' needs could be better fulfilled (Brasil, 1995, p.7).

Therefore, the adoption of a managerial approach fostered the modernization of the public sector by promoting concepts of efficiency, effectiveness, and competitiveness (Secchi, 2009). From this movement toward modernizing the public administration pillars, the governmental strategy has become aware of the citizens real needs, through the strengthening of a multichannel strategy and relationship with citizens (Schellong, 2005).

\subsection{Customer Relationship Management (CRM)}

Relationship marketing may be defined as the attraction, maintenance, and improvement of its relationship with customers (Berry, 1995; Sheth \& Parvatiyar, 2000; Payne, 2012). Authors like Berry (1983) and Gummenson (1994) were some of the first to mention the term and have been used as a basis for research on the subject. For Gummenson (1994), relationship marketing involves networks and interactions, representing a new paradigm in marketing theory. The marketing strategy, which used to focus on customer acquisition and transactions levels, shifted and became aware of aspects like loyalty, personalization and benefits provision.

At present, the principles of relationship marketing are applied in a technological environment where markets are in constant transformation (Payne, 2012). Therefore, the company's competitive advantage is best achieved through not only the knowledge of clients' expectations, preferences and behavior, but also by the establishment of added value (McKenna,1997).

Thus, Customer Relationship Management (CRM) comprises relationship marketing principles and may be defined as a strategy focused on the client, supported by information and communication technologies, that contributes to the company's profitability and clients' retention (Mishra \& Mishra, 2009; Payne, 2012). Kannabiran et al. (2004) argue that the CRM may be seen as a philosophy that focuses on aligning the business strategy towards the customers' needs.

Some of the benefits that may be achieved through the adoption of CRM solutions include quality and personalized services, information, and responsiveness to clients' needs, multichannel integration, segmentation, open communication, and, more importantly clients' insight (AlKhouri, 2012).;

Therefore, the success of implementing a CRM strategy requires decision-makers to strengthen relationships with strategic clients so that shareholder value is achieved. In this context, the use 
BBR

18

104

of information and technology tools to the relationship marketing strategy may result in longterm profitable relationships (Payne, 2012).

In the public sector environment, relationship marketing may also help public managers improve public services delivery. It is known as Citizen Relationship Management (CiRM) and its implementation allows public service providers to manage complaints and citizens' demands, and offer services that are more citizen-oriented, as well as reducing citizens' waiting time (Xavier \& Gouveia, 2004). Public managers should adopt a proactive strategy by using all available data from citizens to anticipate their demands or solve their complaints (Fulla, 2007; Reddick, 2010). Most interactions citizens have with the government are related to moments of their lives and may be predictable through relationship management.

\subsection{Citizen Relationship Marketing (CiRM)}

For Schellong (2005), Citizen Relationship Management (CiRM) may be understood as a strategy, enabled by information and technology tools, focused on citizens, that fosters the establishment and improvement of relationships and promotes citizenship. Unlike its application in the private sector, CiRM in the public sector does not seek primarily to maximize profits, although the management of the relationship with citizens may result in efficiency in the use of public resources (Al-Raisi \& Al-Khouri, 2010). In the public sector, relationship marketing enables public managers to better understand citizens' needs, improve service quality levels, reduce transaction costs, personalize the relationship and meet citizens' demands more effectively, so that service levels are compared to those in the private sector (Xavier \& Gouveia, 2004). As a result, it allows better use of public resources, increasing the governments overall effectiveness (Fulla, 2007).

Some of the barriers to the CiRM implementation may include investment obtention, leadership support, and the need to overcome barriers that underlie the traditional structures of public institutions, where information is stored in silos (Kannabiran et al., 2004). In this regard, for a successful strategy, public institutions should promote not only a cultural change, one which is based on intergovernmental cooperation, but also a multichannel communication approach and process improvement, addressing the problem from the citizen's perspective (Schellong, 2005).

Thus, the adoption of CiRM concepts by the public sector may help them offer better public services. Further, citizens can benefit from shorter waiting times, less frustration in finding the services they need, receiving the results accordinglys and, ultimately, acheiving higher satisfaction (Kavanagh, 2007). But the question is whether citizens may be seen as clients?

\subsection{Citizen-State Relations}

The state-citizen relationship may present various approaches. The main roles given to individuals addressed by scholarly studies include that of constituent (Frederickson, 1991; Richards, 1994; Vigoda, 2002), taxpayer (Richards, 1994), consumer/client (Fotaki, 2009; Frederickson, 1991; Peci et al., 2008; Richards, 1994; Thomas, 2013; Vigoda, 2002), citizen (Fotaki, 2009; Frederickson, 1991; Peci et al., 2008; Richards, 1994; Thomas, 2013; Vigoda, 2002) and partner/co-producer (Fotaki, 2009; Thomas, 2013; Vigoda, 2002).

The role of individuals as constituents emerges with the strengthening of democratic regimes in the western world. In this context, officials are elected by the public who receive delegation and legitimacy to choose and make decisions by constituents regarding aspects of their everyday life (Frederickson, 1991; Richards, 1994; Vigoda, 2002). As for the role of taxpayers, it comes up when governments started facing fiscal constraints in the late 1970s and early 1980s, pushing 
public managers to cut expenses and spend more efficiently, both in order to be more productive, and as a means to meet taxpayers' interests (Richards, 1994).

The public as consumer/client emerges as a result of the limitations brought by the strict managerialism principles, which focused primarily on efficiency gains (Richards, 1994). The Citizen's Charter publication by the English government in 1991 reflects the need for change in the government strategy as to focus more attention to issues related to quality, and to the satisfaction of their citizens (Richards, 1994). The emphasis of the Citizen's Charter was on citizens as 'customers' of public services, and the levels of service provision and standards they could expect to receive (Richards, 1994).

Concerning the debate that places the public as citizens, most scholars and practioners seem to agree with such concept, once such discussion brings aspects related to common values andrights and obligations when it comes to public services provision. Kavanagh (2007) argues that the relationship citizens have with the State is much more complex than a transactional relation performed by a consumer. Besides, Denhardt and Denhardt (2000) state that the public interest is about a dialogue of shared values and not about self-interests put together.

Lastly, the partner/co-producer role played by the public may be seen as the development of new forms of service design. This process reflects the need for flexibility and stronger collaboration between governments and societies, in order to overcome public managers' limitations to deliver public services that meet the citizens 'interests (Vigoda, 2002).

Therefore, by bringing the concept of client to the public realm, it helps public administration understand better service users who are entitled to better services, shorter waiting times and benefits. Nevertheless, it should be stressed that the concept of citizen goes beyond that of client, as citizenship involves multiple, and sometimes conflicting, interests (Denhardt \& Denhardt, 2000; Fotaki, 2009; Thomas, 2013).

\section{METHODS}

The present research is characterized as field, descriptive, and instrumental, of transversal character and multi-method nature. The chosen locus of research was the National Institute of Social Security (INSS), an entity that is part of the Indirect Administration of the Federal Executive Branch, linked to the Ministry of Economy. The INSS is responsible for the operationalization of the recognition of the General Social Security System - RGPS users' rights, through a service network composed of fixed and mobile service units, call center service, and a social security portal on the internet.

At the qualitative stage, with a view to adapting Demo and Pessôa (2015) and Lara and Gosling's (2016) research tools, a semantic analysis, an analysis of judges and a pre-test were performed (Pasquali, 2012). The 16 items of the Demo and Pessôa (2015) scale and the 19 items of the Lara and Gosling (2016) scale were previously analyzed. There were redundancies, similar items, and adaptations in some items, resulting in $24 \mathrm{items} \mathrm{left} \mathrm{for} \mathrm{semantic} \mathrm{analysis.} \mathrm{This} \mathrm{stage}$ was attended by students and professors of graduate studies in Administration at the University of Brasília (8 academic specialists) and technicians from the Ministry of Planning, Development and Management, involved in the discussion of tools for the improvement of public services in Federal Public Administration (4 practical specialists).

In the second instance, the analysis of judges was carried out by means of the realization of 2 focus groups in the months of February and March 2017, with managers and executors of the CiRM in the INSS. The participants analyzed items from semantic validation, in order to adapt them to the measurement of the relationship management in the specific context of the INSS. 
BBR

18

106

Finally, a pre-test was carried out with 18 citizens waiting for service at a Social Security Agency located in the Federal District. After these qualitative analysis steps, the application version of the CiRS Exec was produced, composed of 25 items, as well as the item to evaluate the general level of satisfaction with INSS service, from the Net Promoter Score model proposed by Reichheld (2012).

Regarding the quantitative stage, the target population was citizens who had already made use of some INSS relationship channel. As for the sample, it was characterized as stratified by percentage, which occurs by dividing the population into reasonably homogeneous subpopulations (strata) (Cochran, 2007). In this study, two independent samples were used, the first one used to conduct the exploratory factorial analysis and the second being destined for confirmatory validation (Byrne, 2009).

Regarding the size of the first sample, Tabachnick and Fidell (2013) point out that the exploratory factorial analysis (AFE) should contemplate a minimum of 300 individuals, while suggesting additionally, as a rule, between 5 to 10 subjects per item of the questionnaire. To size the second sample, for the confirmatory factorial analysis (AFC), Hair et al. (2005), Byrne (2009) and Kline (2011) suggested between 10 to 20 subjects per item. In this sense, considering that the application version of the CiRS Exec had 25 items, a minimum of 125 questionnaires answered for the AFE, and 250 questionnaires answered for the AFC was defined.

For the design of the research sampling strategy, considering the chosen locus, which are the social security agencies (APS) located in the Federal District (DF), INSS data regarding the service provided by the institution were used as reference. According to the managers of the INSS, in the DF there are a total of 7 APS, classified according to the volume of service, within typologies A, B, and C.

Thus, in order to obtain representativeness for the population of citizens served in the DF, 1 type-A APS and 2 type-C APS were drawn. For type-B APS, there was no draw, since there is only 1 APS classified in this typology. Regarding the number of responses required, the percentage equivalent to $1 \%$ of the monthly average number of visits per type of APS was defined, given the large number of visits. The final quantity obtained from valid questionnaires was 500 (Medeiros, 2018), which meets the requirements established in the literature.

The data processing process had the analysis of frequency distribution (average, standard deviation, variance, maximum, and minimum) as an initial step, in order to confirm the accuracy of the data transcription. It was not necessary to analyze the missing values, since the application of the questionnaire was done by the researchers themselves, not resulting in answers with blank items. Then, we analyzed the presence of outliers, orvalues that differed substantially from the average and most of the data, using the SPSS (version 21.0.0.0) Mahalanobis distance, according to Tabachnick and Fidell (2013). The procedure was to check the correspondent value at the chisquare table, with level of significance $\mathrm{p}<0,001$, considering the 25 items of the scale. The result was $\mathrm{X}^{2}=52,620$. Then, a regression was conducted, having a counter as Dependent Variable (DV) and the other variables as Independent Variables (IV). The 23 values, with scores above $\mathrm{X}^{2}=52,620$, were excluded from the sample. Further, based on the data analysis chosen for the research, Tabachnick and Fidell (2013) recommend that outliers should be removed.

Finally, the analysis of the assumptions for the use of multivariate analyzes was carried out, as established by Hair, William, Babin and Anderson (2009). Normal probability graphs and residue charts were generated with the objective of verifying the normality, linearity, and homoscedasticity of the data. All assumptions have been confirmed. 
In this sense, the final sample consisted of 477 subjects (Medeiros, 2018). Afterwards, the final sample was randomly divided into two different samples. The first one, for the exploratory factorial analysis (Study 1), was composed of 205 subjects (Medeiros, 2018); and the second one, referring to the confirmatory factorial analysis (Study 2), by means of structural equation modeling, was composed of 272 subjects (Hair et al., 2009; Medeiros, 2018). It should be noted that, for Study 2, multivariate normality was also observed, according to Marôco (2010) criteria, in the Amos statistical program, which did not present any problems. Finally, for the calculation of the index of satisfaction of the citizens with the services provided by the INSS, the methodology of the Net Promoter Score (NPS) was used, established by Reichheld (2012).

Regarding the characterization of the sample, it was found that approximately $64 \%$ of the total respondents were between 35 and 59 years of age. Among the respondents, 52\% were men and $48 \%$ women. Regarding education level, $27.6 \%$ had completed high school education, $17.3 \%$ had completed higher education and $16 \%$ reported incomplete primary education. Participants with some level of specialization (latu or strictu sensu) totaled 11.2\%. Regarding the service channel used (face-to-face, telephone or internet), we verified that face-to-facehad a higher frequency, totaling $95.4 \%$. The second most used channel was the telephone, with $86.7 \%$, followed by the digital channel (portal, email and social networks), with $42.4 \%$.

\section{RESULTS AND DISCUSSION}

\subsection{Qualitative Stage}

The semantic analysis revealed a high level of agreement, either for permanence, addition, exclusion, or fusion, in 21 of the 24 items. In addition, we added a new item 'There is an INSS agency close to me', to measure aspects related to the convenience of the services offered by the INSS. Finally, managers who acted as judges also suggested the inclusion of three new items in the research instrument. It should be noted that the level of agreement of the specialists to the items was $80 \%$, which meets the criteria suggested by Pasquali (2010). In this sense, the application version of the CiRS Exec had 25 items, in addition to the item to evaluate the general level of satisfaction with the INSS service, based on the NPS model proposed by Reichheld (2012).

\subsection{Quantitative STAGe}

\subsubsection{Exploratory validation}

In relation to the results of the quantitative analysis, the psychometric validation of the proposed scale was carried out through the analysis of the main components, in addition to the exploratory factor analysis (AFE). Firstly, the analysis of the main components had an objective to verify the adequacy of the use of factorial analysis for the researched sample, that is, the factorability of the sample. For this, both the correlation matrix and the adequacy index of the sample proposed by Kaiser-Meyer-Olkin (KMO) were analyzed. The results obtained showed significant correlations between the variables and the commonalities values, corroborating with the indication of the matrix factorability. In addition, by means of the calculation of the KMO, an index of 0.91 was obtained, considered as 'wonderful' by the literature (Kaiser, 1974). 
The conduct of the AFE followed the guidelines of Pasquali (2012) from the definition of a set of factors that was not sub- or super-extracted, with a view to minimize distortions of the results undertaken in future analyzes. In this sense, the chosen criteria were eigenvalues, or the percentage of variance explained, the scree plot graph and the parallel analysis. The eigenvalues method greater than 1.0 indicated six factors, and the total variance explained greater than $3 \%$ indicated 11 factors. In addition, by means of the scree plot graph, or sedimentation graph, it was possible to obtain a visual analysis of the eigenvalues graph, allowing us to verify the point where the slope is no longer sharp and becomes almost horizontal (Pasquali, 2012). In this case, the analysis suggested two factors, observing the inflection point.

In order to guarantee the adequacy of the number of factors of the proposed scale, parallel analysis was used, as suggested by Hayton, Allen and Scarpello (2004), as well as the arguments of Horn (1965), who argue that such a technique is accurate in $92 \%$ of cases, allowing a higher level of security in determining the set of values to be extracted.

The value of the random eigenvalues was estimated with the aid of RanEigen software (Enzmann, 1997). The results of the parallel analysis suggested the use of two factors, since the number of factors is indicated when the empirical value is lower than the estimated value (Reise, Waller, \& Comrey, 2000).

Then, the reliability of the 3 items $(5,8$, and 22$)$, was assumed for the second factor, presumably related to information and communication technology (TIC), which was analyzed using Cronbach's alpha. Results above 0.70 are considered reliable and above 0.80 are very reliable (Nunnally $\&$ Berstein, 1994). The alpha result obtained for the 3 items was below 0.6, (0.56), which is the minimum accepted by the international literature. In addition, two of the three items had a shared factorial load, with a small value difference between them. Thus, in the interest of scientific parsimony proposed by Byrne (2012), the option was to consider unifactorial structure for the scale.

In this factor, items with loads above 0.55 were privileged, so that the scale contained only good, very good, and excellent items, making up 15 items. The reliability analysis of the 15 items resulted in an alpha of Cronbach of 0.92, considered of high reliability (Comrey \& Lee, 2013; Nunnaly \& Berstein, 1994). We chose to add items 8 and 22, even with poor and reasonable classifications, respectively, due to the fact that these items are theoretically representative, given the role that TIC plays in the discussion of the CiRM concept. The inclusion of these items did not result in a change in the alpha of Cronbach, which remained at 0.92.

Thus, at the end of the exploratory factorial analysis, the relationship scale proposed for the INSS (CiRS Exec) presented only one factor with 17 items, which confirms the unifactorial structure of the first CiRS, as elaborated by Demo and Pessôa (2015). The classification of the items presented 5 of them as 'excellent', 4 as 'very good', 6 as 'good', 1 as 'regular' and 1 as 'poor', with a high reliability index.

Furthermore, the total variance explained by the 'Relationship with the Citizen' construct was $33.15 \%$, which can be evaluated as a good result, given the unifactorial structure of the scale. Finally, Table 1 presents the consolidated psychometric indexes of CiRS Exec. 
Table 1

Psychometric indexes of the complete version of CiRS Exec

\begin{tabular}{|c|c|c|}
\hline Item description & Factorial load & Quality \\
\hline 10. I am satisfied with the quality of the services provided by INSS. &, 81 & Excellent \\
\hline 11. The INSS attendants solve my requests. &, 75 & Excellent \\
\hline 14. INSS deserves my trust. &, 73 & Excellent \\
\hline 24. I rarely have to go to INSS to resolve my requests. &, 71 & Excellent \\
\hline 15. INSS recognizes the importance of the citizen. &, 71 & Excellent \\
\hline 9. The INSS attendants can answer all my questions. &, 68 & Very good \\
\hline 12. The INSS attendants are quick in solving my requests. &, 67 & Very good \\
\hline 18. INSS listens to my doubts, suggestions and complaints. &, 66 & Very good \\
\hline 7. INSS has effective telephone service. &, 63 & Very good \\
\hline 19. INSS has a positive image towards society. &, 62 & Good \\
\hline $\begin{array}{l}\text { 4. I can follow my requests in the INSS relationship channels } \\
\text { (telephone, internet, face-to-face). }\end{array}$ &, 60 & Good \\
\hline 20. INSS encourages the exercise of citizenship. &, 58 & Good \\
\hline 16. INSS offers personalized service. &, 56 & Good \\
\hline 17. The INSS website meets my needs. &, 56 & Good \\
\hline 13. The INSS attendants are attentive and helpful. &, 56 & Good \\
\hline $\begin{array}{l}\text { 22. INSS offers services to be provided entirely through the } \\
\text { internet. }\end{array}$ & ,49 & Reasonable \\
\hline $\begin{array}{l}\text { 8. INSS offers new technologies to provide its services (social } \\
\text { networks, mobile applications). }\end{array}$ &, 43 & Poor \\
\hline Reliability & \multicolumn{2}{|c|}{0,92} \\
\hline Total Variance Explained & \multicolumn{2}{|c|}{$33,15 \%$} \\
\hline
\end{tabular}

Source: Prepared by the authors

\subsubsection{Confirmatory validation}

Confirmatory factorial analysis was carried out using structural equation modeling (SEM), a likelihood estimation method. The choice of said method was justified by the fact that this is the most commonly used estimation method in SEM, given its robustness to normality problems, as well as efficacy for different sample sizes (Hair et al., 2009).

To verify the adjustment of the model to the sample, indexes are used, and the researcher must use both an incremental index and an absolute index, besides the value of the chi-square and associated degrees of freedom. A model that presents the normalized $\chi^{2}$ value (NC, or CMIN/ $\mathrm{df}$, where CMIN is the statistic of $\chi^{2}$ and $\mathrm{df}$ are the degrees of freedom of the model), CFM (Comparative Fit Index or comparative adjustment index) and RMSEA (root mean square error of approximation) will have enough information for the researcher to evaluate it (Hair et al., 2009).

Thus, according to Kline (2011), satisfactory values for a structural model must meet the following criteria: values for NC (CMIN/DF) between 2.0 and 3.0 and, at most, up to 5.0; values for CFI equal to or greater than 0.90; and values for RMSEA less than 0.06 or up to 0.08 . Based on these parameters, a confirmatory analysis of the exploratory factorial structure obtained previously was carried out, which resulted in low factorial loads, lower than 0.5 , for items 4, 8, 17 and 22. The loads of the four excluded items were 0.480, 0.370, 0.279 and 0.264. 
According to Guadagnoli \& Velicer (1988), factors with 4 or more items with loads above 0.6 are reliable no matter of the sample size. The same authors argue that factors with 10 or more items, with loads above 0.4 , are only reliable if the sample is higher than 150 . Thus, considering a 0.4 load as a cut can be acceptable if the sample is big (or higher than 150 subjects). Although our sample was big (477 subjects), the strategy was, at first, to have only items ranked as good, very good and excellent (loads above 0.55 , according to Comrey \& Lee, 1992). Nevertheless, an exception was made for items with load below 0.55 but with relevant theoretical support, as the theory should always prevail over statistics (Comrey \& Lee, 1992).

However, in order to further improve the adjustment obtained, the modification indexes (I.M.) were also analyzed, according to the guidelines of Kline (2011). The I.M. between the variables I20 ('INSS encourages the exercise of citizenship') and I19 ('INSS has a positive image towards society'), as well as between the variables I20 ('INSS encourages the exercise of citizenship') and I15 ('INSS recognizes the importance of the citizen'), were 29.37 and 17.57 , respectively. Thus, a double arrow was introduced between variables I20 and I19 and between variables I20 and I15.

It is worth mentioning the existence of theoretical support in the literature for the associations made between these items. Vigoda-Gadot, Shoham and Vashdi (2010) argue that a positive image of the public sector can be perceived as an indicator of a strong democracy, a concept that is directly related to citizenship. Moreover, Vigoda-Gadot and Mizrahi (2007) suggest that the image of the public sector is more related to the performance of the state's role, which should guarantee rights and duties, among other things. Thus, a public institution that stimulates citizenship will therefore have a positive image before society.

Similarly, the relationship between the promotion of citizenship and recognition of the importance of the citizen is consistent with the arguments of Denhardt and Denhardt (2000) who, in proposing the concept of the New Public Service, suggest that people should increasingly fulfill their citizen role, and the government should adopt a posture sensitive to the needs of the society.

Thus, the final results obtained for the 13 -item model were $\chi^{2}(63)=159.30, \mathrm{NC}(\mathrm{CMIN} / \mathrm{DF})$ 2.53, CFI 0.94, RMSEA 0.07 and SRMR 0.05. The standardized root mean residual (SRMR) was also calculated, which refers to the absolute mean of the residual correlation, i.e. the difference between observed and predicted correlations, and it is useful for comparing adjustments across models (Hair et al., 2009; Kline, 2011). The literature establishes that good SRMR values should be $\leq 0.08$ (Kline, 2011).

From these results, it is possible to affirm that the scale has a good adjustment, since all the parameters are within the recommendations of Kline (2011). In summary, Figure 1 presents the measurement model obtained in the confirmatory factorial analysis with the respective parameters.

Next, the reliability of the identified factor was analyzed by Jöreskog's rho $(\rho)$, internal consistency measure more recommended than the alpha of Cronbach, for modeling by structural equations, considering that it uses as reference the factorial loads and not the correlations observed between the variables (Chin, 1998). The 'Relationship with the citizen (RCi)' factor obtained $\rho=0.91$, which is considered quite satisfactory, according to Chin (1998), since the Jöreskog's rho index should be higher than 0.7 .

Subsequently, the construct validity of the CiRS Exec was tested by means of convergent validity and nomological validity. The validity of a construct refers to the extent to which a set of measured items reflects the theoretical construct that these items should measure (Hair et al., 2009). It should be noted that the discriminant validity test was not carried out, given the unifactorial structure of the scale. 


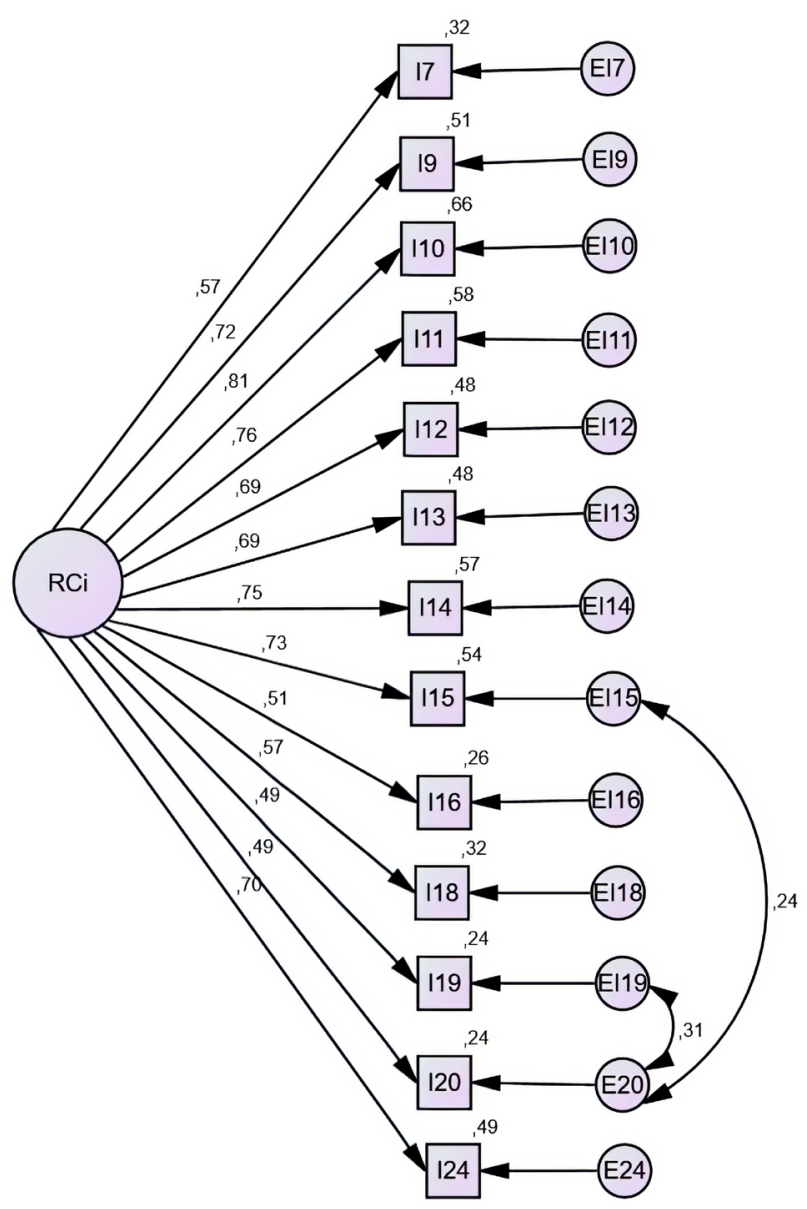

Figure 1. Confirmatory Factorial Analysis.

Note: $\chi^{2}(63)=159,30$, NC (CMIN/DF) 2,53, CFI 0,94, RMSEA 0,07 e SRMR 0,05

Source: Prepared by the authors

The convergent validity refers to the degree of agreement between two or more measurements of the same construct, and the intercorrelations of the items should be at least moderate, above 0.3 (Cohen, 1992; Hair et al., 2009; Kline, 2011). Thus, one of the signs of convergent validity used is the reliability of the factor (Hair et al., 2009), which, in the case of CiRS Exec, was above 0.7 , indicating internal consistency and reliability. Another indicator of convergence established in the literature is the factorial loads, which should be higher than 0.5. It can be stated that CiRS Exec met this criterion in almost all the 13 items that make it up, with the exception of items 19 and 20 , which obtained a factorial load of 0.49 , but which can still be considered significant, according to Hair et al. (2009). With this, it is possible to affirm that the scale has convergent validity.

With the nomological validity, we sought to confirm the ability of the scale to behave in relation to other constructs, as predicted. Then, tests of correlations between constructs, according to the theory, were carried out (Hair et al., 2009). For this, the average of the responses given by the individuals to the 13 items resulting from the final model of the scale was calculated, correlating it to the result of the answers of the subjects interviewed to item 26, relative to Net Promoter Score, 'On a scale from 0 to 10 , indicate your overall level of satisfaction with INSS service care.' 
To conduct the correlation analysis between the aspects described above, the coefficient of Pearson was used, as well as the Spearman coefficient, since the latter allows us to describe the relation between linear data, non-linear data, and ordinal measures (Freund, 2006). The results obtained - Pearson (,725) and Spearman (,757) - demonstrated a high correlation between the constructs (relationship and satisfaction), confirming what was established in the literature, as authors such as Levitt (1990), Bolton (1998), Pollard, Young and Gregg (2006) point out, when they affirm that it is possible to identify a correlation between satisfaction and relationship constructs. Moreover, for Sin, Tse and Yim (2005), the effective implementation of a relationship management strategy allows the improvement of customer satisfaction levels.

Finally, the satisfaction of the citizens benefiting from the INSS services surveyed through the Net Promoter Score (NPS) index was evaluated. For the analysis of citizens' satisfaction, they were asked: 'On a scale from 0 to 10 , indicate your overall level of satisfaction with INSS service care.' The mean of the responses of the total sample was $5.68(\sigma=2.53, M=5)$.

Following the methodology established by Reichheld (2012), the NPS indicator for the INSS was calculated as follows: initially the author suggests to disregard the respondents who assigned scores 7 and 8; then the percentage of the promoters was added, that is, citizens who assigned scores 9 or 10 , which was $16.72 \%$, and, finally, the percentage of detractors (scores 0 to 6 ) was calculated, or , citizens who were assigned scores from 0 to 6 , and whose result was $83.28 \%$. Thus, the final NPS obtained for the INSS was $-66.57 \%$, which is the value of the percentage of the promoters subtracted from the percentage of the detractors.

This result shows that the number of detractors, that is, those users dissatisfied and disappointed with the treatment they received, and potential critics of the institution, together with their family and friends, greatly exceeds the number of promoters, who are those that represent the success of the institution. This diagnosis draws the attention of INSS managers, since the adoption of a CiRM strategy presupposes both the encouragement of citizenship and the improvement of the image of the public institution (Demo \& Pessôa, 2015; Schellong, 2005). In this sense, a larger contingent of promoter citizens, who assign high scores to the services of a public institution, may represent greater satisfaction of users of public services (Lee, 2012).

Therefore, given that satisfaction is an indicator of profitable relationship strategies, it is necessary to seek to increase the satisfaction level of citizens who use the services offered by the government, with a view to the effectiveness of this relationship management strategy with citizens (Bolton, 1998; Levitt, 1990; Pollard et al., 2006). Therefore, for its simplicity of calculation, the NPS is a useful tool for INSS managers to assist in the monitoring of citizens' perception of the services offered by Social Security Agencies.

\section{IMPLICATIONS, LIMITATIONS AND AGENDA}

Our study verified that it is indeed possible to measure the attributes of a relationship model with citizens in the Federal Executive Branch, based on the INSS experience. CiRS Exec obtained good indications of validity and reliability, both exploratory and confirmatory. Based on the analyzes carried out, the unifactorial structure of the first CiRS developed by Demo and Pessôa (2015) was confirmed in the context of the Judiciary Branch, which presented good psychometric items, and high reliability, which translated into external validity and indications of generalization. In this perspective, being the specific case of the INSS, it is the responsibility of INSS managers to undertake efforts in the design of guidelines that strengthen the institution's relationship with its users, especially in the context of increasing demands of citizens, which reflects the exercise of their citizenship pillar of the CiRM, resulting in higher quality public services. 
Regarding the limitations of the study, CiRS Exec represents a first attempt to develop a confirmatory scale model of CiRM designed specifically for the context of the public service, especially for the Federal Executive Branch. Consequently, the results so far collected are more indicative than conclusive, so that new validations are welcomed in different spheres of government and powers, culture and countries, to provide even greater external validity and generalization to the measure.

Another limitation is related to the cross section of the study. Although exploratory and confirmatory validations were performed, the development of a time series database would be opportune to test the structure obtained here from a longitudinal perspective, presenting as a gain the improvement of its psychometric items. Thus, continuous validation of the CiRS is necessary, based on new trends and perspectives, in the theoretical field of the CiRM, which also contemplates changes in the context of public organizations.

Besides, considering that there are records in the literature (e.g. Keiningham et al. 2007; Kristensen \& Eskildsen, 2014) that criticize the fact that managers rely solely on the NPS results to assess the level of customer satisfaction, the NPS was used in the research as an alternative for its simplicity of measurement and the institution's own interest in a simple measure of satisfaction for service users. Therefore, we suggest, as a recommendation, that the NPS should be associated with other satisfaction assessment methodologies in further studies.

Furthermore, the quantitative step of applying the CiRS Exec instrument was carried out only in the presence channel, that is, in Social Security Agencies located in the Federal District. Thus, in view of the multichannel premise suggested by the CiRM strategy, we suggest that the instrument should be applied in other INSS relationship channels, such as telephone and internet, in order to obtain a more reliable picture of the citizens' perception in relation to the relationship initiatives of the entity.

Also, the lack of conceptual coherence on the part of the authors, who often see the CiRM strategy as the simple adoption of a technological solution, is an opportunity for future studies that address the standardization of terminology about CiRM. With this, it allows the strategy of managing the relationship with citizens not to be confused with initiatives of total quality or electronic government (Schellong, 2008).

Along the same lines, the development of studies on issues of varied public policies, such as health, transportation, and security, can bring new elements to the discussion of the relationship management with citizens, allowing the identification of the existence of different approaches depending on the public policy of a specific public service. Regarding this aspect, it is suggested to investigate whether the normative framework that guides the provision of the service influences the quality of care, especially regarding the uniformity of information on the part of the attendance team.

In addition, since much of the scientific production related to the CiRM has been published in journals specialized in information and communication technology (TIC), especially international ones (Medeiros, 2017, p. 26), there is a great opportunity to encourage the exploration of the relationship marketing theme in the public sector, by conducting calls in periodicals outside the TIC area, especially national ones. 
BBR

18

114

\section{CONCLUSION}

Despite the limitations described, we concluded that we achieved the main objective of this research, which was to identify indications of validity and reliability of a relationship scale with the citizen. In addition, an important path of study possibilities is opened, privileging citizens as protagonists in the process of designing and offering services, as well as seeking the establishment of an integrated governance structure, attentive to the real needs of society, which will, ultimately, contribute to strategic and effective relationship management.

In terms of theoretical contributions, this study enables future relational studies on the subject, such as in other public bodies, contexts, and levels, which may enhance the external validity and generalization of the measurement scale herewith proposed. Concerning the methodology, this research has evolved by applying advanced statistical methods for measurement validation, or , confirmatory analysis, through structural equation modeling. Given that the Citizen Relationship Scale (CiRS) validation conducted by Demo and Pessoa (2015) has been exploratory, this study has sought to confirm the exploratory structure previously obtained, which may grant reliability and external validity.

\section{REFERENCES}

Al-Khouri, \& Ali M. (2012), Customer Relationship Management: Proposed Framework from a Government Perspective. Journal of Management and Strategy, 3(4).

Al-Raisi, A.N., \& Al-Khouri, A. M. (2010). Public Value and ROI in the Government Sector. Advances in Management, 3(2), p. 33-38.

Berry, L. L. (1983). Relationship Marketing. In Emerging Perspectives on Services Marketing. Eds. Leonard L. Berry, G. Lynn Shostack, and Gregory Upah. Chicago, IL: American Marketing Association, 25-8.

Berry, L. L. (1985). Relationship marketing of services-growing interest, emerging perspectives. Journal of the Academy of Marketing Science, 23(4), p. 236-245.

Bolton, R. N. (1998). A dynamic model of the duration of the customer's relationship with a continuous service provider: the role of satisfaction. Marketing Science, 17(1), p. 45-65.

Byrne, B. M. (2009). Structural equation modeling with AMOS: basic concepts, applications, and programming (2nd ed.). New York: Routledge.

Byrne, B. M. (2012). Structural equation modeling with Mplus: Basic concepts, applications, and programming. New York: Routledge Academic.

Câmara da Reforma do Estado da Presidência da República. (1995). Plano Diretor de Reforma do Aparelho do Estado. Brasília, Distrito Federal, Brasil.

Chin, W. W. (1998). The partial least squares approach to structural equation modeling. Modern methods for business research, 295(2), p. 295-336.

Cochran, W. G. (2007). Sampling techniques (3rd ed.). New York: John Wiley \& Sons.

Cohen, J. (1992). A power primer. Psychological Bulletin, New York, 112(1), p. 155-159.

Comrey, A. L., \& Lee, H. B.(2013). A first course in factor analysis. Nova York: Psychology Press.

[dataset] Medeiros, J. C. E (2017). Mendeley Data, v1. https://doi.org/10.17632/xwj98nb39r.1 
Demo, G., \& Pessôa, R. (2015). CRM na Administração Pública: desenvolvimento e validação de uma Escala de Relacionamento com o Cidadáo (ERCi). Revista de Administração Pública. Rio de Janeiro, 49(3), p. 677-697.

Denhardt, R. B., \& Denhardt, J. V. (2000).The New Public Service: Serving Rather than Steering. Public Administration Review, 60(6), p. 549-559.

Enzmann, D. (1997). RanEigen: A program to determine the parallel analysis criterion for the number of principal components. Applied Psychological Measurement, 21(3), p. 232.

Fotaki, M (2009). Are all consumers the same? Choice in health, social care and education in England and elsewhere. Public Money Manage, 29(2), p. 87-94

Frederickson, G. H. (1991). Toward a theory of the public for public administration. Administration \& Society. 22(4), p. 395-417.

Freund, J. E. (2006). Estatística aplicada: economia, administração e contabilidade. Porto Alegre: Bookmann.

Fulla, S. L. (2007). The citizen and CRM. In: S. C. Kavanagh (Ed.). Revolutionizing constituent relationships: the promise of CRM systems for the public sector. (pp. 20-24). Government Finance Officers Association, Chicago, IL, USA.

Guadagnoli, E., \& Velicer, W. F. (1988). Relation of sample size to the stability of component patterns. Psychological Bulletin, 103(2), p. 265-275. https://doi.org/10.1037/0033-2909.103.2.265

Gummesson, E. (1994). Making Relationship Marketing Operational. International Journal of Service Industry Management, 5(5), p. 5-10

Hair, J. F, Jr, Babin, B., Money, A. H., \& Samouel, P. (2005). Fundamentos de métodos de pesquisa em administração. São Paulo: Artmed.

Hair, J.F., Jr, William, B., Babin, B., \& Anderson, R.E. (2009). Análise multivariada de dados (6th ed.). Porto Alegre: Bookman, 2009

Hayton, J. C.; Allen, D. G., \& Scarpello, V. (2004). Factor retention decisions in exploratory factor analysis: A tutorial on parallel analysis. Organizational research methods, 7(2), p. 191-205.

Hood, C. (1991) A public management for all seasons. Public Administration 69(1), p. 3-19.

Hood, C. (1995). The 'New Public Management' in the 1980s: variations on a theme. Accounting, Organizations and Society, 20 (3), pp. 93-109.

Horn, J. L. (1965). A rationale and test for the number of factors in factor analysis. Psychometrika, 30 (2), pp. 179-185.

Kristensen, K., \& Eskildsen, J. (2014). Is the NPS a trustworthy performance measure? The TQM Journal, 26(2), p. 202-214.

Kannabiran, G., Xavier, M.J., \& Anantharaaj, A. (2004). Enabling e-governance through citizen relationship management - concept, model and applications. Journal of Services Research, 4(2), p. 223-240.

Kavanagh, S. C., (2007). An introduction to CRM. In: S. C. Kavanagh (Ed.). Revolutionizing constituent relationships: the promise of CRM systems for the public sector. (pp. 9-19). Government Finance Officers Association, Chicago, IL, USA.

Kline, R. B. (2011). Principles and practice of structural equation modeling (3rd ed.). New York: The Guilford Press. 
BBR

18

116

Lara, R. D., \& Gosling, M. S. (2016). Um modelo de gestáo do relacionamento entre os cidadãos e a administração pública. REAd, 84(2), p. 332-364.

Lee B. (2012). The hidden wealth beyond Net Promoter. Harvard Business Review.

Levitt, T. (1990). A imaginação de marketing (2nd ed). São Paulo: Atlas, 1990.

Marôco, J. (2010). Análise de equaçóes estruturais. Lisboa, Portugal: ReportNumber.

Mckenna, R. (1997). Marketing de Relacionamento - Estratégias bem-sucedidas para a era do cliente (6th ed). Rio de Janeiro: Campus.

Medeiros, J. C. E. (2017). Como mensurar os atributos de um modelo de relacionamento no Poder Executivo Federal: indicios de validade e confiabilidade de uma escala de relacionamento com os cidadãos. (Unpublished master's Thesis). Universidade de Brasília, Brasília, DF, Brasil.

Medeiros, J. C. E. (2018). Database for the exploratory and confirmatory analyses. Mendeley Data, v1. http://dx.doi.org/10.17632/vjsht9scg4.1 [dataset]

Mishra, A., \& Mishra, D. (2009). Customer Relationship Management: implementation process perspective. Acta Polytechnica Hungarica, 6(4), p. 83-99.

Nassif, T. (2004) U.S. General Services Administration. Office of Citizen Services and Communications. Newsletter, Citizen Relationship Management, 14.

Nunnally, J. C., \& Bernstein, I. H. (1994). Psychometric theory (3rd ed.). New York: McGraw-Hill.

Pasquali, L. (2010). Instrumentos psicológicos: manual prático de elaboração. Laboratório de Pesquisa em Avaliação e Medida (LabPAM) - Instituto de Psicologia. Brasília: Universidade de Brasília, Brasília, Distrito Federal, Brasil.

Pasquali, L. (2012). Análise fatorial para pesquisadores. Laboratório de Pesquisa em Avaliação e Medida (LabPAM) — Instituto de Psicologia. Brasília: Universidade de Brasília, Brasília, Distrito Federal, Brasil.

Payne, A. F. T. (2012). Handbook of CRM: achieving excellence in customer relationship management. Oxford: Elsevier.

Peci, A., Pieranti, O. P., \& Rodrigues, S. (2008). Governança e New Public Management: convergências e contradiçóes no contexto brasileiro. Organizaçóes \& Sociedade, Bahia, 15(46), p. 39-55.

Pollard, C., Young, J., \& Gregg, P. (2006). Towards a Simplified Framework of CRM for Use in Public and Private Sectors. Journal of Information Technology Case and Application Research, 89(2), p. 24-38.

Pollit, C; Dan, S. (2013). Searching for impacts in performance-oriented management reform: A review of the European literature. Public Performance \& Management Review, 37(1), p. 7-32.

Reddick, C. G. (2010). Impact of Citizen Relationship Management (CRM) on Government: Evidence from U.S. Local Governments. Journal of E-Governance, 33, p. 88-99.

Reichheld, F. F. (2012). A pergunta definitiva 2.0: Como as empresas que implementam o net promoter score prosperam em um mundo voltado aos clientes. Rio de Janeiro. Elsevier.

Reise, S. P., Waller, N. G., \& Comrey, A. L. (2000). Factor analysis and scale revision. Psychological assessment, 12(3), p. 287.

Richards, S. (1994). El Paradigma del cliente en la gestión pública. Tradución por: Joan Bubirats Humet. Gestión y Análisis de Políticas Públicas, (1), p. 5-16. 
Schellong, A. (2005). CRM in the public sector: towards a conceptual research framework. National Conference on Digital Government Research. Atlanta, GA, USA.

Schellong, A. (2008). Citizen Relationship Management: a study of CRM in government. Peter Lang.

Schellong, A., \& Langenberg, T. (2007). Managing citizen relationships in disasters: Hurricane wilma, 311 and Miami-dade county. System Sciences. HICSS 2007: 40th Annual Hawaii international Conference, Hawaii, HI, USA.

Secchi, L. (2009). Modelos organizacionais e reformas da administração pública. Rev. Adm. Pública, Rio de Janeiro, 43(2).

Sheth, J. N.; Parvatiyar, A. (2000). The domain and conceptual foundations of relationship marketing. In: Sheth, J. N.; Parvatiyar, A. (Org.). Handbook of relationship marketing. Sage Publications, pp. 3-38.

Sin, L. Y. M., Tse, A. C. B., \& Yim, F. H. K. (2005). CRM: conceptualization and scale development. European Journal of Marketing, 39(11/12), p. 1264- 1290.

Tabachnick, B. G., Fidell, L. S. (2013). Using multivariate statistics. (6th ed). Boston: Pearson Allyn And Bacon.

Thomas, J. C. (2013). Citizen, Customer, Partner: Rethinking the Place of the Public in Public Management. Public Administration Review, 73(6), p. 786-796.

Vigoda, E. (2002). From responsiveness to collaboration: Governance, citizens, and the next generation of public administration. Public Administration Review, 62(5), p. 527-540.

Vigoda-Gadot, E., \& Mizrahi, S. (2007) Public sector management and the democratic ethos: A longitudinal study of key relationships in Israel. Journal of Public Administration Research and Theory 18, p. 79-107.

Vigoda-Gadot, E., Shoham, A., \& Vashdi, D. R. (2010). Bridging bureaucracy and democracy in Europe: A comparative study of perceived managerial excellence, satisfaction with public services, and trust in governance. European Union Politics 11(2), p. 289-308.

Xavier, J., \& Gouveia, L. B. (2004). O relacionamento com o cidadão: A importância do território. In: Conferencia ibero-americana. Retrieved from http://homepage.ufp.pt/lmbg/com/xavier_iadisibero04. pdf 